\title{
¿De qué hablamos cuando aspiramos a educar para el desarrollo en América Latina ${ }^{2}$
}

\author{
What Are We Talking About When We Aim to Educate for Development in Latin America? \\ ¿De que falamos quando aspiramos a educar para o desenvolvimento em América Latina?
}

\section{Resumen}

Pensar en el papel de la educación para el desarrollo en el contexto latinoamericano nos pone en la vía de hacer referencia a eso que se ha llamado desarrollo. Una noción tan elástica y polisémica que su contenido se ha llegado a desvirtuar hasta convertirlo en muchas cosas, distintas entre sí. A veces es una quimera, un mito, una falsa promesa, bajo la cual se han llevado adelante políticas que no han resultado positivas para el devenir de nuestros pueblos. Otras, con menor frecuencia, la noción de desarrollo ha permitido un abordaje integral, una hoja de ruta, donde los desafíos económicos, sociales, políticos, culturales, científicos y educativos han podido conjugarse en forma sinérgica y se han puesto en marcha procesos que resultan en diversas formas de alcanzar incrementos en el bienestar general y colectivo. Por esto, apuntalar muy bien el sentido, alcance y significado del esquivo término desarrollo es fundamental para encaminar una discusión seria de cómo podemos educar a una sociedad o a nuestras sociedades latinoamericanas, para construir progresivamente otra ruta hacia una prosperidad bien compartida. Así pues, este artículo se propone abonar el terreno en esa dirección.

Palabras clave: Educación para el desarrollo, desarrollo, sociedades latinoamericanas y caribeñas, desigualdades.

Recibido: 1 de junio, evaluado: 10 de junio, aprobado: 12 de junio

1 Científica social puertorriqueña con B. A. en Economía de la Universidad de Puerto Rico, Río Piedras, y maestría y doctorado en Desarrollo Económico y Social, Universidad de Londres. Ha realizado una gran cantidad de investigaciones sobre la realidad económica y social de Puerto Rico y de América Latina y el Caribe. Se ha destacado por sus investigaciones sobre desarrollo socioeconómico, pobreza y desigualdad y sobre género y la subordinación de las mujeres, así como por su trabajo en el diseño, instrumentación y evaluación de políticas sociales. Fundadora y directora durante quince años del Centro de Estudios de la Realidad Puertorriqueña (Cerep). En 1991 asumió la dirección general del Consejo Latinoamericano de Ciencias Sociales clacso, la red académica de investigación social más importante de América Latina y el Caribe, con sede en Buenos Aires, Argentina. Es consultora frecuente de organismos del sistema de Naciones Unidas, especialmente de unesco, unIFEM y pNud. Ha sido jefa de la Delegación de Puerto Rico en reuniones oficiales de la Comisión de Población y Desarrollo de la cepal, organismo regional de la onu. En la actualidad se desempeña como investigadora y directora de proyectos del Instituto Latinoamericano de Educación para el Desarrollo (Ilaedes), en Uruguay y Puerto Rico. Correo electrónico: marcia.rivera.hernandez@gmail.com

2 Este texto es producto de la conferencia ofrecida en la conmemoración del x aniversario del Centro de Educación para el Desarrollo, UNIMINUTO Sede Principal (Bogotá), el 11 de agosto de 2016. Esta es una versión editada y autorizada por la autora. 


\begin{abstract}
Thinking about the role of education for development in the Latin American context places us in the path of referring to what has been called development. A notion so broad and polysemic that its content has become distorted into many things different from each other. Sometimes it is a chimera, a myth, a false promise, under which policies have been carried out that have not been positive for the future of our peoples. Others, less frequently, have allowed an integral approach, a road map, where the economic, social, political, cultural, scientific and educational challenges have been combined in a synergetic way and started processes that result in various ways to achieve increases in general and collective well-being. For this reason, it is fundamental to fortify the meaning and scope of the elusive term development, in order to direct a serious discussion of how we can educate a society or our Latin American societies, to progressively build another route towards wellshared prosperity. Therefore, this article aims to prepare the ground in that direction.
\end{abstract}

Keywords: Education for development, development, Latin American and Caribbean societies, inequalities.

\title{
Resumo
}

Pensar no papel da educação para o desenvolvimento no contexto latino americano põe-nos na via de fazer referência ao que se chama desenvolvimento. Uma noção tão elástica e polissêmica que seu conteúdo se chegou a se desvirtuar e converter-se em muitas coisas, diferentes entre sim. Às vezes é uma quimera, um mito, uma falsa promessa, ao qual se levaram adiante políticas que não têm resultado positivas para o devir de nossos povos. Com menor frequência, a noção de desenvolvimento tem permitido uma abordagem integral, onde os desafios econômicos, sociais, políticos, culturais, científicos e educativos têm podido converter-se em energia sinérgica, e se puseram em marcha processos que resultam em diversas formas de atingir incrementos no bem-estarsocial. Por isto, sustenta muito bem o sentido, alcance e significado do termo desenvolvimento, é fundamental para encaminhar uma discussão séria de como podemos educar a uma sociedade ou a nossas sociedades latino americanas, para construir progressivamente outra rota para prosperidade bem compartilhada. Por conseguinte, este artigo propõe-se fertilizar o terreno nessa direção.

Palavras-chave: Educação para o desenvolvimento, desenvolvimento, sociedades latinoamericanas e caribenhas, desigualdades. 
Sabemos que América Latina es una región de enorme complejidad y diversidad. Si bien comparte características comunes positivas, como el hecho de tener al español como el idioma de mayor difusión y la de poseer una fuerte base de capital social, también comparte otros elementos negativos, como ser la región con mayor desigualdad social del mundo. Por ello no podemos caer en la trampa de hablar de la región como un todo monolítico; cada país latinoamericano tiene su propia historia, cultura, recursos, organización y visiones de mundo. Para confirmar esto basta recordar que en Guatemala se hablan todavía veintidós lenguas de origen maya, además de los idiomas con reconocimiento oficial: el español, el garífuna y el XINCA (Ministerio de Educación de Guatemala, s.f.). Si bien somos muy parecidos, las experiencias de la colonización española, de la construcción de los Estados nacionales y también de las dictaduras que muchos de los países de América Latina tuvieron, han dejado huellas diferentes en cada uno.

Ahora cuando vivimos la era de la rápida e intensa globalización tecnológica que impacta la economía y las sociedades, podemos afirmar que a pesar de ello persisten disparidades significativas entre los países de la región. Y también sigue habiendo, y se han acentuado, las diferencias entre ciudad y campo, entre montaña y costa, y entre sectores sociales en términos del acceso a bienes y servicios generados por el proceso globalizador. Incluso en los países más pequeños de la región, como las islas del Caribe, suele haber diferencias entre las poblaciones de la montaña y la costa, tanto en formas de organizar la producción, acceso a tecnología, costumbres, prácticas sociales y en visiones de mundo. La globalización tecnoeconómica tal vez nos ha tocado a todos, pero en distintos niveles e intensidades.

\section{Las persistentes desigualdades en América Latina y el Caribe}

El inicio del siglo xxI fue testigo del surgimiento de nuevos procesos políticos en la región, dirigidos a impulsar transformaciones multidimensionales para gestar-según se planteaba- sociedades más equitativas, dinámicas en su capacidad de crecer, que aseguraran un buen nivel de calidad de vida a sus poblaciones, así como una nueva y más sana relación con la naturaleza. Ello fue impulsado como respuesta a los desastrosos resultados de las políticas neoliberales de austeridad y de 'ajuste estructural' que fueron instrumentadas desde mediados de los años ochenta hasta finales de los noventa en casi todos los países de la región. El grueso de los análisis de esos años mostraron que el cuasi desmantelamiento del aparato estatal para lograr crecimiento económico a través de ajustes fiscales y del traspaso de muchas de las funciones al sector empresarial privado fueron ineficaces en lograr los objetivos deseados.

Por el contrario, según dan cuenta numerosos informes internacionales, en los años noventa se incrementaron significativamente los niveles de pobreza y, sobre todo, de desigualdad en la región de América Latina y el Caribe en general (CEPAL, 2015). El aumento en desempleo, marginación y exclusión social llevó al surgimiento de fuertes movimientos sociales que reclamaban alternativas políticas y económicas que no significaran asfixia para las clases trabajadoras. En Chile, Venezuela, Argentina, Brasil, Uruguay, Nicaragua, Bolivia, El Salvador, República Dominicana, además de la histórica Cuba, la población comenzó a votar por un cambio de signo y a elegir a candidatos, candidatas, partidos y alianzas con propuestas de impulsar otro tipo de desarrollo, otro tipo de sociedad. Comenzó entonces a recuperarse el sentido de la palabra para significar procesos integrales dirigidos a que todas las personas puedan participar del proceso de construcción de una sociedad con bienestar y equidad.

El advenimiento del nuevo siglo XxI vino, pues, aparejado de la instalación de nuevos gobiernos en varios países de la región, cada cual con propuestas propias y diferentes entre sí, aunque algunos analistas los hayan agrupado bajo la denominación genérica de 'progresistas'. Era la hora de la esperanza para la región, pues el objetivo de erradicar la pobreza y ganar en equidad podía ser el mejor estímulo para lograr paz y acercarse al resto del 
mundo. La realidad es que había, y sigue habiendo, diferencias muy importantes entre los gobiernos de este grupo de países y en su afán simplista los medios de comunicación tendieron a generalizar las denominaciones de populistas, socialistas o comunistas, 'colando' tras ello un intento de demonizar dichos procesos que recién se instalaban. Cuando se buscaba descalificar a uno, se ha solido inferir que todos tienen o tendrán las mismas 'fallas' -léase corrupción, incapacidad administrativa, limitación de derechos o libertades, o lo que fuere que se considere se aparta de un proceso neoliberal democrático-.

Sin duda, en la pasada década y media ha habido avances notables en el empeño de varios países de avanzar hacia sociedades más incluyentes, más solidarias y equilibradas, y los datos así lo confirman. La región en su conjunto avanzó significativamente en asegurar el acceso a la educación; adelantó en la creación de oportunidades laborales para las mujeres; redujo en la mayoría de los países la indigencia y la vulnerabilidad de buena parte de sus familias; mejoró sus indicadores de salud; y en muchos casos se generaron opciones de vivienda digna para las familias más necesitadas. También se afirmaron los procesos electorales que definen las democracias formales y se afirmó la voluntad de lograr la integración regional.

Si bien estas son conquistas importantes, todavía estamos lejos de los resultados esperados y el camino para avanzar ha estado 'plagado' de dificultades. Más preocupante aún es que las perspectivas hoy son más inciertas, tanto por factores externos ligados a la evolución de la economía y la paz mundial como por problemas internos, particularmente la corrupción, que sigue siendo un 'flagelo' por superar, no solo por la debilidad de los mecanismos de control en la mayoría de los países, sino por la proclividad de las empresas transnacionales de utilizar el soborno de funcionarios para lograr grandes contratos. Mucho más debe cambiar para poder construir una región definida por su compromiso con la igualdad de oportunidades y de condiciones para todas las personas, por la equidad en todas sus dimensiones, por el reconocimiento y respeto pleno de la diversidad y de los derechos humanos, la defensa del patrimonio ambiental, así como por el intercambio horizontal entre las naciones de la región. Estamos mejor, sin duda; pero lejos de haber encontrado la ruta óptima hacia otro tipo de sociedad, donde la riqueza y los recursos, las oportunidades y las condiciones de vida estén más equitativamente distribuidas y las personas podamos compartir mayor calidad de vida, de tranquilidad, de paz y de felicidad y no solo de bienes de mercado ${ }^{3}$.

La complejidad de los problemas, la multidimensionalidad de los desafíos y la diversidad de actores -internos y externos- que hoy inciden en los procesos económicos, sociales, políticos y culturales han hecho y continúan planteando un reto permanente para nuestros países. En esta breve presentación quisiera abordar con ustedes lo que considero son los puntos clave para tener en cuenta en el proceso de incidir, desde un ámbito educativo, en la necesaria transformación de las políticas públicas y en la praxis humana para gestar sociedades que permitan a las personas gozar de paz y libertad para optar y decidir; para potenciar sus talentos y capacidades; para aportar al bienestar colectivo; y, sobre todo, para vivir en armonía con la naturaleza. Porque de eso, justamente, es de lo que se trata el desarrollo, visto desde una perspectiva muy distinta de la que había ocupado el espacio de esta denominación.

Entonces, para abordar el tema que me han solicitado es imprescindible hacerse dos preguntas: i) ¿qué vamos a entender por desarrollo? y ii) ¿qué educación necesitamos para gestar ese otro tipo desarrollo que consideramos imprescindible?

3 A la fecha de la revisión de este artículo varios de los países mencionados enfrentan ofensivas desestabilizadoras de partidos y grupos de oposición neoliberal, aun cuando sus resultados económicos sigan siendo buenos. La corrupción de la mano de las grandes empresas transnacionales ha sido efectivamente una tentación funesta para la consolidación de las nuevas alternativas de desarrollo que se venían explorando. 
Comenzaré, primero, abordando algunas cuestiones del polémico y contencioso concepto que es el desarrollo, y les adelantaré desde el inicio mi deseo de deconstruirlo para resignificarlo. Porque hoy, como dijimos, el concepto de desarrollo quiere decir cualquier cosa; su significado se ha 'licuado', se ha distorsionado, se ha hecho una generalización vacua y sin precisión. Por ello, conocer bien la evolución del concepto es de suma importancia para recuperar, dinamizar y dar nuevo contenido al vocablo, sabiendo que su propia naturaleza nos obliga a reconocerle un cierto grado de elasticidad y polivalencia, justamente para que pueda profundizarse en el contenido.

Hasta finales del siglo XIX las corrientes dominantes del pensamiento económico liberal en el mundo manejaban el concepto de riqueza acuñado por Adam Smith y David Ricardo como el indicador clave de prosperidad o decadencia de las naciones. Luego, las principales escuelas de economía de las universidades occidentales generaron nuevas nociones y consolidaron en el debate la noción de crecimiento económico, y establecieron mediciones del dinamismo de una economía nacional a través del producto interno bruto y del ingreso per cápita. Pero fue la Segunda Guerra Mundial la que indujo nuevas reflexiones y el surgimiento de un cambio paradigmático en cómo se aborda la cuestión del progreso o la prosperidad de una sociedad.

Una de las primeras voces en plantear la necesidad de articular las estrategias, medidas y políticas económicas, sociales y culturales en un proyecto integral de desarrollo fue la del padre dominico Louis Joseph Lebret (Francia, 1897-1966), quien en 1941 fundó en su país el movimiento Economía y Humanismo. En el empeño de lograr cambiar la mirada prevaleciente de un capitalismo que, según él, conducía a la desigualdad, a la guerra y a la muerte, Lebret trabajó 'afanosamente' en tres dimensiones, a saber: en el ámbito eclesiástico, en donde logró que la Iglesia católica asumiera posiciones de lucha contra la pobreza y la desigualdad en el Concilio Vaticano ir y en la preparación de la encíclica Populorum Progreso, de la cual fue uno de los principales artífices. También trabajó junto con religiosos musulmanes, asiáticos y africanos desde una visión ecuménica para adelantar esta visión, que implicaba la posibilidad de convivencia entre diferentes y no las relaciones de explotación que caracterizaban la estrategia de crecimiento bajo los parámetros del capitalismo de libre mercado. Durante años, el padre Lebret trabajó afanosamente en investigaciones científicas para refinar su propuesta, así como en divulgación y promoción de la idea de economía humana a nivel internacional. Tuvo en el economista François Perroux un colaborador de excelencia y juntos propusieron la ruta de una economía comunitaria para la reconstrucción de Francia tras la guerra, una estrategia que buscaba respetar la naturaleza y la dignidad de las personas y que fuera 'equilibrada'.

Para entonces, ya otros filósofos como Immanuel Kant, Soren Kierkegaard, Jacques Maritain, y Emmanuel Mounier habían escrito ensayos planteando la primacía del ser humano sobre la economía de mercado. Mounier, fundador del movimiento personalista, llegó a plantear que la economía debe organizarse en función de las personas, y no al revés, y concedió enorme importancia a la vida de las personas en comunidad (Mounier, 1949). Pero, sin duda, fue Perroux quien impulsó el principio de que "el desarrollo de las personas debe ser para ellas y por ellas mismas", noción que fue tomada como eje de los primeros informes sobre desarrollo humano del Programa de Naciones Unidas para el Desarrollo (PNUD) a principios de los años noventa del siglo Xx. Esto fue de suma importancia para comenzar a afincar una noción más compleja, rica, coherente e integral del vocablo desarrollo.

Las nociones de desarrollo humano y de desarrollo humano sostenible que se han manejado en el sistema de Naciones Unidas a lo largo de las pasadas tres décadas han permitido impulsar un cambio conceptual importante, en el sentido de concebir a las personas como eje de los procesos de transformación económica y social y no al capital, a la nación o a los gobiernos. Sin embargo, si bien el debate para ir redefiniendo el concepto ha sido 
intenso en experiencias ricas, también ha estado 'plagado' de dificultades porque, efectivamente, hay muchos en el mundo que se oponen a que el desarrollo sea pensado en función de las personas y no del capital.

El propio sistema ONU no ha logrado una integración real de esta noción en sus proyectos a nivel nacional. Cuando se inició el ejercicio de preparar el primer informe sobre desarrollo humano a principios de la década del noventa no prosperó la incorporación de las variables relacionadas al medioambiente en dicha formulación. También había resistencia de algunos países en relación al papel de los derechos humanos en una teoría general sobre desarrollo. Han sido las organizaciones de la sociedad civil a nivel mundial quienes han reconocido la importancia de estos aspectos y han luchado sin cesar por su incorporación para una visión De ahí que sigamos encontrando mucha fragmentación, duplicación de esfuerzos y dispersión en cuanto al tema de desarrollo dentro de la onU. Ello se reflejó en el insuficiente impacto que tuvieron Objetivos de Desarrollo del Milenio promulgados en el 2000 y su eventual sustitución por los Objetivos de Desarrollo Sostenible, promulgados en 2015.

Desde 1992 el PNUD ha seguido con su propuesta de desarrollo humano y concentra su atención en la generación de índices en tres dimensiones: educación, salud y trabajo e ingresos. Si bien a lo largo de los años ha ido perfeccionando la metodología para generar índices diversos y más precisos, le ha costado agregar otros ámbitos de medición más innovadores, como se está haciendo desde otros espacios de trabajo. Por su parte, desde mediados de los noventa el Programa de las Naciones Unidas sobre el Medio Ambiente (PNUMA) comenzó a usar la noción de desarrollo sostenible, entendiéndolo como uno que satisface las necesidades de la generación presente, sin comprometer la capacidad de las generaciones futuras de satisfacer sus propias necesidades. En años recientes ha volcado su atención a temas como el impacto del cambio climático, la sostenibilidad ambiental, la disposición de desechos, manejo de ecosistemas, entre otros.
La Oficina del Alto Comisionado de las Naciones Unidas para los Derecho Humanos también ha desplegado un gran esfuerzo para incidir en los debates y las políticas de desarrollo desde las normas de los derechos de las personas y ha hecho aportes muy interesantes para definir los umbrales necesarios de derechos humanos, civiles, económicos, sociales y culturales de las personas.

Si bien los aportes del sistema de Naciones Unidas han sido fundamentales, el debate teórico sobre desarrollo ha ido mucho más allá de ese ámbito y hoy presenta desafíos nuevos y algunos 'reciclados'. Del mismo han emergido algunos consensos que ya no generan tanta polémica. Por ejemplo, cuando hablamos hoy de desarrollo, ya queda claro que no estamos hablando de un proceso que calibra si hubo aumento o disminución de los ingresos de un país, como solía hacerse cuando se equiparaban desarrollo y crecimiento económico. Esa visión simplista ocultaba muchas cosas que inciden en el bienestar de las personas que no asegura el mero crecimiento económico. Felizmente, ya nos hemos dado cuenta de ello.

Ahora estamos en una etapa de poder hablar de otra dimensión del desarrollo. Una que yo defino como un desarrollo humano integral y sostenible; un proceso que permite la generación de un entorno proclive a que las personas puedan progresivamente desarrollar plenamente sus talentos y capacidades y llevar adelante una vida en paz, libre de coerción, creativa y productiva, de acuerdo con sus necesidades, visiones e intereses, en armonía con su cultura y cosmovisión y con la preservación del medioambiente.

Para que esa noción de desarrollo se convierta en nuevas formas de organizarse la sociedad y asegurar que la vida sea más equitativa en todas las dimensiones, necesita estar sustentada en principios fundamentales, como los siguientes:

- El reconocimiento y pleno respeto de los derechos individuales y colectivos, incluyendo los derechos civiles, económicos, sociales y culturales. 
- El ejercicio responsable de la ciudanía, que implica deberes hacia las todas personas y colectivos.

- La participación activa de las personas en la definición de sus propias prioridades de vida y en la toma de decisiones que afecten su vida cotidiana.

- La sostenibilidad en el tiempo y la mejora permanente y progresiva de prácticas sociales y económicas que profundicen valores de solidaridad, compartir, interactuar y reconocer al prójimo/a como a uno/a mismo/a.

Si bien hoy muchas personas podemos suscribir, endosar, promover y hacer nuestros esos principios, la realidad es que la mayor parte de las poblaciones latinoamericanas y caribeñas seguimos viviendo en sociedades dominadas por la incertidumbre, la inseguridad, el miedo, el estrés, la frustración, el rechazo intuitivo a lo desconocido y la violencia. Es decir, una vida cotidiana llena de adversidad agobiante, cuyos impactos sobre la salud física y mental son graves y están muy subvalorados.

Tener las necesidades básicas satisfechas, estar bien, en paz, feliz, rodeado de afecto y de estímulos positivos, con capacidad de desplegar libre y creativamente los talentos y capacidades que tenemos, es cada vez más un privilegio que un derecho humano, tanto en Colombia, como en mi Puerto Rico natal; es igual en América Latina que en casi todo el resto del mundo.

Como los seres humanos poseemos eso que se ha denominado resiliencia -esa capacidad de adaptación frente a la adversidad, que tiene de sobra la población de Colombia y muchas poblaciones en América Latina y el Caribe-, nos hemos acostumbrado a vivir en contextos que no aportan un alto nivel de calidad de vida. La resiliencia nos permite asumir con flexibilidad situaciones límite y sobreponernos a ellas, lo que nos permite afrontar situaciones potencialmente traumáticas y hasta nos hace creer que hemos salido fortalecidos de ellas (Linares, 2014). A través de la resiliencia acabamos encontrando la forma de 'bregar' -en el estricto sentido puertorriqueño del términodándole la vuelta o manejando con creatividad los riesgos, amenazas y dificultades para aceptarlas o neutralizarlas. En el proceso -y sobre todo en la región caribeña- solemos utilizar el humor, la música y la 'camaradería', que constituyen señas de identidad y formas de liberación del estrés y que nos permiten navegar con un cierto grado de soltura en las crisis. Para las personas resilientes no existe una vida dura, sino momentos difíciles. Y no se trata de una simple disquisición terminológica, sino de una manera diferente y más optimista de ver el mundo, que devela una actitud de que después de la tormenta llega la calma. Pero generalmente la resiliencia oculta un importante grado de negación (de fuga hacia adelante) o de inconsciencia sobre la gravedad de la realidad y de lo insalubre y 'dañina' que resulta ser la vida cotidiana hoy.

Sin duda, la resiliencia nos facilita el sobrevivir, pero considero que nos ayuda poco a poner en marcha los cambios que necesitamos impulsar para lograr otro tipo de sociedad porque adormece el cuestionamiento. Demostrar resiliencia ha devenido en una cualidad que de maneras insospechadas, además de ayudarnos a superar momentos angustiosos, también inhibe una respuesta que ayude a encontrar una solución final a un problema. En una sociedad sometida a altos niveles de estrés y de incertidumbre, como pueden ser Colombia o mi país, Puerto Rico, la resiliencia puede coexistir con la amnesia funcional o disociativa, una condición que genera en los individuos un distanciamiento de la realidad (que no es lo mismo que pérdida de la realidad, como ocurre en la psicosis). Según muchos expertos en el tema, la disociación es un mecanismo de defensa que consiste en escindir elementos disruptivos para el yo del resto de la psique. Esto se traduce en que el sujeto convive con fuertes incongruencias, sin lograr tener consciencia de ello (Chaudhury et al., 2013; Mascayano, Maray \& Roa, 2009).

Por las dificultades que han tenido los proyectos políticos progresistas y a falta de una buena formación ciudadana en principios y visiones alternativas, en las últimas décadas buena parte de la 
población ha internalizado y asumido como propios y naturales los valores y normas del capitalismo neoliberal. Por ejemplo, se ha llegado a pensar que la desigualdad, la pobreza, o la explotación, son cosas naturales en la vida, y se ha instalado un conformismo atroz, que se refuerza en los contenidos de la educación en todos sus niveles. Si bien en la región hemos tenido grandes pensadores y educadores, con una visión crítica, que han buscado estimular el pensamiento cuestionador, la realidad es que por fuerzas del 'mercado mundial educativo' nuestros currículos desde primaria hasta el nivel universitario acaban subsumidos en una lógica de complicidad con la llamada globalización, dominada por el signo neoliberal. En esa visión, a la que tantas personas adhieren por inercia o por inconsciencia, todo puede y debe ser un negocio; los alumnos son clientes; la competitividad es lo que nos salvará; la empresa privada hace mejor las cosas que los gobiernos; no se necesita regular los mercados porque ellos se ajustan a sí mismos; la riqueza se multiplica con la especulación, no con la producción de conocimiento, bienes y servicios. Ello ha llevado a un proceso de 'naturalización' de los valores y principios que rigen la vida cotidiana en el inhumano capitalismo salvaje, según lo denominó el papa Juan Pablo II, en su encíclica Centesimus Annus, de mayo de 1991. Por eso, es imprescindible que desde una instancia universitaria como esta, nacida de una visión crítica de las consecuencias de ese capitalismo depredador y fundamentada en principios sólidos de respeto a la dignidad humana, compromiso con la equidad y promoción de la solidaridad, se fortalezcan los espacios, instancias y procesos de investigación para comprender el impacto que sobre la sociedad colombiana están teniendo las políticas que sostienen una globalización capitalista desigual, antidemocrática y desintegradora a nivel nacional, que nos ha llevado a pensar que progreso y modernidad (o incluso, desarrollo) es tener un Burger King o un McDonald's en cada esquina de una ciudad.

El estudio serio de los complejos procesos de globalización que están en marcha demostraría cuán contrarios estos son a la vida sana y permitiría aportar al desarrollo de nuevas estrategias para asegurar otro futuro para Colombia. Sin duda, hay muchos aspectos positivos de la globalización, relacionados, por ejemplo, con los notables avances en investigaciones científicas y el acceso que podemos tener a ellas. Pero también hay una contracara de la globalización que va develándose en variados ámbitos.

Por ejemplo, investigaciones económicas señalan el impulso de esta sobre la desigualdades. Lejos de reducirse o eliminarse, con la globalización las desigualdades de América Latina se han disparado: de ingresos, de riqueza, de oportunidades, de condiciones. Con la globalización los recursos naturales de la región se han hecho apetecibles para las grandes empresas transnacionales que buscan minerales y agua y han generado nuevas confrontaciones nacionales sobre cómo, cuándo y quiénes deben tener acceso a los mismos. La globalización también ha servido para sostener y estimular conflictos armados y es responsable del crecimiento de las industrias de ilícitos que generan beneficios astronómicos, alentando el lavado y resguardo de dinero en paraísos fiscales que son ancla del injusto sistema financiero mundial que hoy tenemos.

Estudiar seriamente el impacto de los procesos de globalización sobre la economía, la gente y los procesos culturales de un país es una asignatura imprescindible del proceso de construir un proyecto nacional alternativo desde la gente, para la gente y por la gente. De ahí resulta fundamental tener las capacidades instaladas para acometer ese desafío y que podrán contar con el apoyo de redes académicas de la región que trabajan sobre el tema. En esa dirección, mi primera recomendación es la siguiente: generar una linea de trabajo permanente de investigación, formación y difusión sobre las desigualdades que se verifican en Colombia y en la región, analizando las que pueden incidir en reducirla significativamente. Esto sería una especie de observatorio permanente, que puede ser clave para el éxito del proceso de pacificación en Colombia y para instalar una mudanza hacia un nuevo paradigma de desarrollo en el país. 
El segundo desafío ineludible para lograr un desarrollo humano integral, como el que podemos imaginar y soñar, es generar un diagnóstico cabal de la realidad económica, social, política, territorial, educativa y cultural del país. Las investigaciones que puedan hacerse desde el campo de las ciencias humanas y sociales deben abordar esta cuestión desde la complejidad y la transdiciplinariedad, reconociendo la multiplicidad de actores relevantes que inciden en los procesos. Además, en la coyuntura en que está Colombia, donde la paz se abre como una construcción posible y deseable aunque difícil, el asunto es especialmente urgente.

Colombia es una sociedad donde se verifican desigualdades profundas, crónicas -por su perduración en el tiempo- y diversas. Es el segundo país más desigual de América Latina y el Caribe, precedido por muy poco margen por Honduras, a pesar de que, en términos de PIB, los colombianos están 74 puestos por encima de los hondureños según confirman todas las mediciones del Banco Mundial, del Programa de Naciones Unidas para el Desarrollo y la CePAL También tiene la mayor participación del 1\% más rico en el ingreso total y la concentración de la riqueza ha crecido consistentemente desde 2004. Hoy el $1 \%$ de la población captura más de una quinta parte de la riqueza total del país.

En el índice de desarrollo humano de la ONU, Colombia pierde diez puntos una vez que se lo pondera en términos de desigualdad de acceso a la salud, la educación y bajos salarios. A pesar de haber logrado reducir la proporción de población que se domina 'bajo el nivel de pobreza', la desigualdad se mantiene igual. Esto quiere decir que el producto del crecimiento económico que ha tenido no se distribuye adecuadamente para reducir la desigualdad inmoral que persiste. $Y$ vale resaltar -porque ustedes todos lo saben- que el país todavía tiene una alta proporción de población vulnerable o que vive bajo el nivel de pobreza, así como una alta proporción de indigencia $(28,5 \%$ en el primer caso y $8 \%$ en el segundo). Estos porcentajes son altos en comparación con otros países de la región, pero son altísimos en comparación con la dotación de recursos naturales y humanos que tiene Colombia $\mathrm{y}$ con el potencial que tiene para generar otra realidad. Lo que más impresiona de Colombia son las desigualdades que persisten a lo largo del tiempo en el campo. El índice desigualdad de concentración de la tierra ha seguido aumentando a lo largo de los años y es hoy de 0,91; el mayor de la región y de casi todo el mundo.

Colombia muestra también un bajo nivel de gasto social. El gasto social por habitante que hace el Estado colombiano es menos de la cuarta parte de lo que se invierte en promedio en el resto de Latinoamérica, según la CePAL (2015). Este es de apenas 400 dólares por habitante (poco más de un millón de pesos colombianos), frente a 1.841 dólares por habitante (5,4 millones de pesos) que es el promedio en toda la región.

Este déficit muestra al menos dos cosas: por un lado, prioridades presupuestarias equivocadas a lo largo de muchos años que han privilegiado el gasto militar sobre el social. Para el año fiscal 2015, el presupuesto de Colombia destinó el 13\% de sus recursos a la guerra y usó para ello cerca de 30 billones de pesos. ¡Cuántas escuelas, centros de salud, actividad educativa, deportiva y cultural se podrían hacer con esos recursos! Confiamos en que el fin de la guerra pueda liberar esos recursos y los mismos se utilicen para poner en marcha programas que apoyen el desarrollo humano.

El bajo nivel de recursos asignados al ámbito social es también reflejo de la renuencia a usar la política fiscal para mejorar la distribución del ingreso. Y aquí hay otros datos sumamente importantes de analizar en relación con América Latina y el Caribe. Colombia aplica una tributación del $16 \%$ del PIB, mientras que el promedio regional es de $23 \%$, que sigue siendo una tasa baja en comparación con el resto del mundo. Por ejemplo, Europa tiene una tasa promedio de tributación del 46\% y Estados Unidos, de 42\%. En Colombia también parece haber un uso inefectivo de los impuestos a la propiedad porque prevalecen exenciones y deducciones a los más pudientes y porque hay un régimen tributario ineficaz que permite la evasión 
de impuestos medios y altos. Además, por la alta tasa de informalización que prevalece, la base del sistema tributario es 'chica' con relación a la población total.

A nuestro juicio, Colombia necesita diseñar un proceso serio y abarcador de la formalización del trabajo y de los negocios y la extensión de la cobertura de la protección social para poner en marcha un cambio en política fiscal que pueda contribuir a reducir desigualdades. Urge también fortalecer los mecanismos de negociación colectiva y las instancias de diálogo social, a fin de mejorar la calidad de los empleos y reducir la desigualdad. Un buen ejemplo de políticas en esa dirección son las que ha adoptado el Uruguay, país que en la última década logró dotar de protección social a segmentos importantes de la población más pobre. Hoy, allí el 100\% de los 'peones' rurales y el 100\% de las empleadas domésticas tienen salarios mínimos dignos y están cubiertos por el sistema de protección social que les asegura un jornal con horas determinadas, vacaciones, salario vacacional, pago de horas extras, inclusión en el sistema universal de salud y acceso educativo gratuito en todos los niveles, incluyendo el universitario. Esa y otras políticas redistributivas han generado logros formidables de eliminación de la miseria, reducción de la pobreza de $15 \%$ a $4 \%$ entre 2002 y 2014 y reducción de la brecha de desigualdad.

Los países de la región que mejores resultados han tenido en reducir pobreza, vulnerabilidades y desigualdad en la región han buscado combinar las transferencias monetarias destinadas a asegurar determinados niveles de vida con condicionalidades orientadas a favorecer el aumento de las capacidades humanas, políticas y programas tendientes a mejorar la inclusión laboral. También han buscado generar programas de apoyo al autoempleo, a la creación de cooperativas con base territorial y a las micro y pequeñas empresas. Además, mejoraron la coordinación intergubernamental de las políticas sociales e incorporaron a organizaciones sociales en la instrumentación de políticas públicas, lo que aportó mayor eficiencia, transparencia y eficacia al gasto público. En todos los casos también se verifica la expansión del enfoque de derechos en la política pública, que se manifiesta en la construcción de sistemas de protección social integrales y tendientes a la universalización. Esta me parece una lección importante para Colombia y genera una base de experiencias para el análisis y la reflexión académica del tema de las desigualdades, que considero urgente.

La desigualdad en Colombia, como en muchos otros países de la región, se manifiesta también en la distribución espacial de la población, el uso y la apropiación del territorio. Las personas que viven en condiciones de indigencia, pobreza o vulnerabilidad enfrentan múltiples barreras para insertarse en empleos de calidad de manera sostenible. Las dificultades en el acceso al trabajo decente están fuertemente marcadas por los determinantes de género, raza y etnia, así como por ciertos momentos del ciclo de vida -en particular, la juventud-, la condición de discapacidad y la residencia en áreas rurales.

David Harvey, una de las voces más influyentes de las ciencias sociales desde la geografía, ha demostrado que la segregación espacial hace que los barrios segregados suelan tener problemas de acceso a los colegios, que los servicios de salud sean pésimos, que el sistema de recolección de basura no funcione bien y que la gente viva en un entorno urbano desastroso. Todo ello genera un estado de adversidad que se reproduce generación tras generación y que limita seriamente el desarrollo humano y suele estigmatizar a las personas por el lugar donde viven. En las comunidades carenciadas normalmente hay una alta tasa de desocupación y una de las pocas maneras de ganar dinero es entrando al negocio de la droga. Las oportunidades reales para superar ese estado de vulnerabilidad son muy restringidas. La segregación urbana y la manera en que la ciudad está organizada generan prejuicios, que no solo afectan la calidad de vida, sino las oportunidades reales que las personas tendrán a lo largo de su vida.

Para erradicar las diferencias sociales y superar la segregación hay que reorganizar la ciudad desde 
líneas más democráticas, tal como fue el objetivo del movimiento El minuto de Dios en sus inicios. El modelo urbano del capitalismo neoliberal produce desigualdades que yo he llamado 'de origen', de la cuna de las personas, que son las más difíciles de superar por su capacidad de reproducirse generacionalmente. Necesitamos un urbanismo más igualitario y por ello es tan importante el trabajo y la organización a nivel barrial, tal como lo privilegia esta institución. El desarrollo alternativo que queremos y que necesitamos debe estar asentado en el territorio, ya que es ahí donde reside el poder de la gente.

La desestructuración urbana, sumada a las precariedades de empleo y habitacionales, representan un freno a la evolución de un país en su conjunto. La dimensión territorial juega un papel fundamental junto a las características de las familias, las peculiaridades de las políticas públicas, y el mercado formal e informal, en definir las posibilidades de reducir los niveles de desigualdad en un país.

Salir de ese entramado, de lo que se reconoce ya como 'el perverso círculo de reproducción de las desigualdades' requiere, no solo de cambios en las políticas públicas, sino también de un profundo cambio de paradigma y de cambio cultural, que reconozca que la exclusión es un flagelo de la humanidad.

¿Cuáles serían, entonces, los elementos centrales de un nuevo paradigma de desarrollo? Por ahora les debe quedar claro que tenemos que comenzar por demoler lo que hasta ahora se ha considerado desarrollo. Un mito, un espejismo, que se nos ha vendido como tautología, como una ruta que todas las naciones deben emprender para alcanzar un estadio similar. Ello en sí mismo plantea tantos problemas y encarna tal simplismo que no quiero aburrirlos en repasarlos. Baste decir que la característica más general y compartida que podemos tener en el mundo es justamente la diferenciación: en cosmovisiones, identidades, características poblacionales, lenguajes, comportamientos, y un largo etcétera.
Por esto, es imprescindible afirmar que no hay una ruta trazada en piedra, inamovible e idéntica para que todas las sociedades puedan garantizar lo más básico que es la dignidad humana, el respeto a los cuerpos, las identidades, y los derechos fundamentales a gozar de alimentación, salud y un medioambiente sano. El desarrollo debe ser visto como una construcción social, que es dinámica, cambiante, justamente porque se centra en las personas y la diversidad es lo que caracteriza a la humanidad. Pero podemos identificar unos principios que pueden servir de marco de orientación para asegurar que la sociedad en su conjunto comparta los frutos del esfuerzo individual y colectivo.

La nueva conceptualización del desarrollo debe tener un enfoque integral; es decir, no se trata solo del aspecto económico, como se entiende ahora, sino que debe incluir todos los aspectos que inciden en que las personas tengan bienestar, paz, alegría, tranquilidad y que puedan legar esos bienes intangibles a las futuras generaciones. La propuesta de centrarnos en trabajar en la definición de un desarrollo alternativo afirma la necesidad de que los seres humanos tengan una relación fluida y armónica con la naturaleza y que puedan reconocerse como parte de ella. Por eso es imprescindible también asegurar que el medioambiente y todos los recursos naturales se usen con prudencia y sentido de responsabilidad para que no se agoten y puedan ser utilizados por las futuras generaciones.

Desde esta visión, de lo que se trata es que comencemos a construir un terreno de oportunidades para que cada ser humano pueda desarrollar sus capacidades y talentos; para que pueda aprender a aprender, aprender a ser y aprender a hacer. Como educadores tenemos que diseñar programas e iniciativas para ayudar a crear condiciones para que todas las personas puedan gozar de buena salud y de integridad física; que puedan participar en todas las instancias de decisiones que afecten sus vidas. Que se les reconozca y puedan ejercer sus derechos fundamentales en un marco de dignidad inviolable. 
La gran pregunta es cómo comenzar a hacerlo, cuando tenemos tanto viento neoliberal, globalizador, en contra. ¿Cómo lograremos erradicar la especulación como valor, la ética del todo se vale, el consumismo, la exclusión social y la discriminación étnica-social? ¿Cómo ayudar a que la gente comprenda la perversa lógica del mercado y del negocio definido por reglas de avaricia y deseo de lucro y se disponga a contribuir a desarticular los mercados que nos dominan, desde el financiero hasta los de ilícitos como la droga y la trata humana? ¿Cómo afirmar y defender la paz mundial para poder vivir en paz personal, familiar y comunitaria? Yo soy empedernida optimista: todo ello se puede lograr, porque tenemos una fuerte base, que es nuestra propia gente, que está repleta de capital social que no sabe cómo utilizar para su propio bienestar. Y tenemos instituciones, como UNIMINUTO, que lleva años trabajando desde una visión similar a la que les estoy planteando. Insisto, entonces, en que no hay una receta única para la ruta por trazar y que podemos dibujarla con el insumo de todos y todas, desde los principios generales que hemos señalado.

Por tal motivo, uno de los mayores desafíos para la inclusión social es lograr la articulación y armonización entre la política económica, las políticas productivas y laborales y la política social. Sin embargo, muy pocas instituciones universitarias en la región forman para que esa visión se convierta en orientadora de las políticas públicas y las prácticas sociales. Considero imprescindible que desde el sistema educativo comencemos a formar para construir otra realidad regional. El trabajo en equipos inter y transdisciplinarios es esencial para poner esos cambios en marcha.

\section{Desafíos y posibilidades de la educación para un nuevo paradigma de desarrollo}

Habiendo discutido -aunque muy someramente- de qué desarrollo estamos hablando, paso ahora a hilvanar algunas ideas de cómo formar para ese nuevo paradigma de desarrollo, especialmente refiriéndome a su papel en la academia colombiana.

La sociedad colombiana hoy discute con intensidad, y en su gran mayoría pone muchas esperanzas en la construcción de un proceso de paz, que permita superar los conflictos y la violencia que se acarrean desde hace más de siete décadas. La paz es un objetivo loable, necesario, pero no llegará en piloto automático, aunque sea refrendada por la gran mayoría de los colombianos. La paz no se logra meramente por un acuerdo político; debe construirse día a día por toda la sociedad y requiere de cambios notables en prácticas políticas, estatales, comunitarias, familiares y personales. Generar paz requiere también atender los reclamos que generó la violencia, entre ellos superar las abundantes desigualdades que persisten en Colombia y generar mejores condiciones de vida para toda la población, especialmente para las más vulnerables. Y en setenta años fue poco lo que se avanzó en ese desafío, según les comentara antes. Me parece, entonces, que el gran reto, desde el punto de vista de la educación, es ligar la construcción de la paz con la construcción de un nuevo paradigma de desarrollo.

A continuación, presento un diagrama que recoge los elementos centrales de lo que considero es un nuevo acercamiento para examinar y potenciar las interrelaciones entre los diversos factores que inciden sobre esta forma de entender el desarrollo, de cara a un desarrollo humano sostenible. El mismo es producto de numerosas investigaciones y trabajos prácticos que he podido desarrollar a lo largo de casi cuarenta años en muchos países de la región. He encontrado que ayuda a entender las sinergias que pueden darse entre ámbitos diversos y que parte de la premisa de que por cualquier lado se pueden hacer intervenciones que pongan procesos virtuosos en marcha. De esa manera queda erradicada la idea de la ruta única que dominó el debate de los años sesenta y setenta y del pensamiento único neoliberal que nos acecha desde los ochenta. 
Figura 1. Puntos de entrada para estimular el desarrollo humano sostenible

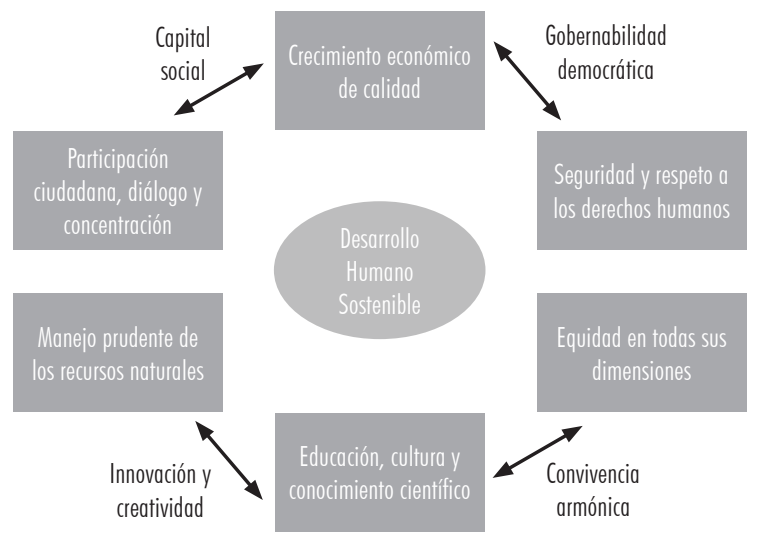

Fuente: elaboración propia (2015).

Encuentro que hay seis ejes o factores fundamentales que inciden en el desarrollo humano sostenible (véase figura 1). A través de políticas públicas bien diseñadas para incidir en estos factores se puede generar la sinergia necesaria para entrar en un proceso virtuoso hacia el desarrollo humano. Estos ejes son los siguientes: seguridad y respeto a los derechos humanos; equidad en todas sus dimensiones; promoción de la cultura y el conocimiento científico; manejo prudente de los recursos naturales; participación ciudadana y diálogo social; y crecimiento económico de calidad, lo que implica estrategias de diversificación de la matriz productiva, así como de los mercados. De la interacción de esos factores se pueden esperar resultados importantes, como lo son la generación de capital social, la posibilidad de gobernabilidad democrática, la convivencia armónica y cohesión social y una cultura proclive a la innovación y a potenciar la creatividad del ser humano. Puesto en marcha el proceso sinérgicamente, se aumentarían las posibilidades de lograr una sociedad donde el desarrollo humano sostenible sea una realidad. Por supuesto, en cada uno de los ámbitos hay numerosos factores que deben considerarse, sobre los cuales también hemos trabajado.

Para finalizar, quiero reiterar $\mathrm{mi}$ convicción de que Colombia tiene extraordinarios ríos subterráneos de creatividad, bondad, solidaridad y capacidades en todos los órdenes de la vida que pueden mover la rueda del cambio. La puesta en marcha del proceso de paz es señal de que se está quebrando la inercia de tantos años y que se ha comenzado un proceso de cambio. Hay que aprovechar el momento para insertar el debate sobre paz y otro desarrollo. Si no se hace, se pone en peligro a las generaciones futuras porque avanzará la reproducción de la vulnerabilidad, se destruirá el medioambiente con las industrias extractivas y la desigualdad hará la convivencia imposible.

\section{Referencias}

Balbi, J. (2001). onGs, gobernancia y desarrollo en América Latina y el Caribe. Programa Gestión de las transformaciones sociales -MOST / unesco. Documentos de debate, (53). París.

Ballon, E. (1997). ONG, sociedad civil y desarrollo. En Los desafíos de la cooperación. Lima: DESCO.

Banco Interamericano de Desarrollo. (2006). Informe sobre el Progreso Económico y Social. Washington.

Castells, M. (2003). Observatorio global. Crónicas de principios de Siglo. Barcelona: Libros de Vanguardia.

Cernea, M. (1988). Non-governmental Organizations and Local Development. Washington: World Bank Discussion Paper.

CEPAL, (2015). Panorama social 2015. Santiago: CEPAL: Recuperado de http://repositorio. cepal.org/bitstream/handle/11362/39965/1/ S1600227_es.pdf

Chaudhury, S., et al. (2013). Dissociative Trance Disorder: A Clinical Enigma. Unique Journal of Medical and Dental Sciences, 1(01), 12-22.

Linares, R. (2014). Resiliencia: Los doce hábitos de las personas resilientes. Revista Digital El Prado Psicólogos. Recuperado de http://www.elpradopsicologos.es/blog/resiliencia-resilientes/

Mascayano, F., Maray, F., \& Roa, A.(2009). Trastornos disociativos: una pérdida de la integración. Recuperado de https://es.scribd.com/doc/98561858/ Trastornos-Disociativos-Carola-Rivero 
Mounier, E. (1949). Le personnalisme. Louvain La Neuve. Recuperado de http://personnalisme. org/files/le_personnalisme.pdf

Rivera, M. (Ed.). (2010). Avances y necesidades en el fortalecimiento de la sociedad civil uruguaya. Uruguay: Proyecto [J].
Zapata, J. (2009). Coordinación y gestión territorial delapolitica social en Colombia. Santiago: CEPAL. Serie Políticas sociales (148). Recuperado de http://caucacolaborativa.gov.co/sites/default/ files/documentos_espacioaprendizaje/sps148politica-social-Colombia.pdf 